\title{
Sistema Web Aplicado à Genética de Populações
}

\author{
Naiara Silva dos Santos \\ Dept. De Ciências e \\ Tecnologias \\ $U E S B$ \\ Jequié, Bahia, Brasil \\ nssantos@uesb.edu.br \\ Edes Lázaro P. dos Santos \\ Dept. De Ciências e \\ Tecnologias \\ UESB \\ Jequié, Bahia, Brasil \\ edes_lazaro@gmail.com \\ Claudio Lúcio Fernandes Amaral \\ Dept. De Ciências Biológicas \\ UESB \\ Jequié, Bahia, Brasil \\ materdidatic@gmail.com
}

\author{
Lucas Santana Nunes \\ Dept. De Ciências e \\ Tecnologias \\ $U E S B$ \\ Jequié, Bahia, Brasil \\ snlucas7@gmail.com \\ André Andrade Santos \\ Dept. De Ciências e \\ Tecnologias \\ $U E S B$ \\ Jequié, Bahia, Brasil \\ whoisandrade@gmail.com
}

\author{
Bruna Silva \\ Dept. De Ciências e \\ Tecnologias \\ UESB \\ Jequié, Bahia, Brasil \\ bubysilva_8@gmail.com
}

Wellington da Conceição

Ribeiro

Dept. De Ciências e

Tecnologias

UESB

Jequié, Bahia, Brasil

12ribe@gmail.com
Resumo - Este trabalho tem o objetivo de auxiliar, estudantes e pesquisadores, na precisão dos cálculos sobre genética populacional, por meio de um software educativo: o Popgenelation. As técnicas de melhoramento genético trazem diversos benefícios, porém frequentemente para chegar a resultados satisfatórios, é necessária a realização de cálculos de equações complexas e que geralmente são solucionadas, pelos estudantes e pesquisadores, sem o auxilio de um sistema informatizado. Além disso, os sistemas existentes que realizam cálculos similares, porém não específicos para a genética de população, são pagos ou possuem restrições de acesso e não possuem caráter educativo, ou seja, sua usabilidade não é satisfatória. Diante do exposto, verifica-se a necessidade de aumentar a confiabilidade e precisão dos cálculos feitos por pesquisadores (da área de Genética), além de automatizar essa etapa com a ajuda de um sistema informatizado e ainda auxiliar estudantes que necessitam aprender o conteúdo de genética populacional via um software educativo. A pesquisa é metodológica, pois se refere à realidade, e nos leva a caminhos, formas ou procedimentos para alcançar um determinado fim. E aplicada, pois tem um objetivo concreto que é o software de melhoramento genético, que visa sanar um problema real, logo é algo prático, com uma solução concreta. Os resultados encontrados pela análise dos questionários evidenciaram a usabilidade do sistema, caracterizando-o como um software educativo.

Palavras-chave: software educativo, melhoramento genético, usabilidade.

\section{INTRODUÇÃO}

A revolução tecnológica ocorrida no Século XX gerou uma grande difusão nas mais diversas áreas do conhecimento, permitindo uma grande interação entre pessoas e as máquinas, auxiliando o trabalho e automatizando os mecanismos de gestão, isso implica em melhoramento no desempenho além da facilidade no manuseio e confiabilidade no que se refere aos dados gerados. Não é diferente na área de melhoramento genético, os softwares, desenvolvidos são de grande utilidade nas pesquisas e aprendizado dos profissionais, e isso está em constante crescimento.

É de grande importância à inclusão de paradigmas de ensino nos diversos campos de pesquisas, gerando efeitos positivos nos estudantes, segundo Skinner [1] a instrução programada ou máquina de ensino, estimula os alunos a estudar sem a intervenção direta do professor.

Com o grande uso dessas tecnologias, a modalidade de auto ensino, ou ensino programado, vem tomando seu espaço no mercado como um auxiliador em pesquisas, tornando a compreensão sobre os assuntos abordados maior, reforçando o aprendizado dos estudantes e professores, visto que em diversas situações é mais viável reproduzir simulações ou possibilidades no campo virtual [2]. Para tanto, é necessário criar softwares que possuam facilidade de uso, um exemplo da carência desse tipo de software está na página da Universidade de Rockefeller, http://lab.rockefeller.edu/ott/geneticsoftware, o usuário 
é redirecionado para a página onde o Dr. Wentian Li lista, que até outubro de 2019 continham mais de 600 softwares na área de biologia, organizados por ordem alfabética e com suas respectivas descrições. Analisando essa lista é possível perceber que a maioria dos softwares são desenvolvidos em C, C++ e Pascal, que não proporcionam muitos recursos gráficos para ajudar no mecanismo ensino-aprendizagem.

Para a realização de estudos acerca de genética populacional é necessário ter conhecimento sobre diversos temas, a fim de determinar de que maneira os mecanismos evolutivos, como mutação, recombinação, seleção natural, migração, atuam sobre as populações naturais. Essa infinidade de possibilidades de combinações de alelos se torna uma tarefa bastante árdua para ser calculada de forma manual, necessitando de ferramentas que sejam capazes de facilitar o trabalho humano para que evitem a fadiga visual, além de promover a confiabilidade dos cálculos.

Portanto, o sistema desenvolvido tem como característica atender as necessidades de autoaprendizagem do estudante, por meio de um ambiente agradável, atuando no auxílio a resoluções de problemas como cálculos de frequências de genes autossômicos e não autossômicos, tornando um software de caráter educativo.

É de relevância esse trabalho, pois visa automatizar cálculos complexos antes feitos de forma manual, auxiliando pesquisadores e estudiosos, por meio de um sistema informatizado de caráter educativo, atendendo as métricas da Organização Internacional para Padronização, ISO 9126 quando se refere à usabilidade.

O Popgenelation, nome que foi dado ao projeto, se divide em dois módulos, são eles: o teórico e o prático, sendo o teórico voltado ao público que tem menor conhecimento na área e busca melhorar seu entendimento e reforçar seu aprendizado na área das ciências biológicas, pois contém diversas explicações e demonstrações dos assuntos abordados. 0 módulo prático visa auxiliar o desenvolvimento de projetos no ramo das ciências biológicas, contando com cálculos precisos sobre genética de população, analisando as frequências dos alelos e influências como, forças evolutivas, seleção natural, mutação e derivação gênica.

\section{REVISÃO DA LITERATURA}

O homem vive em uma busca constante as condições para melhoria do solo, antigamente por meio de observação e experimentação, atualmente utilizam-se técnicas mais sofisticadas como análises de solo, para obter resultados satisfatórios. Para existir melhoramento é necessário haver uma grande diversidade genética, que possibilite desenvolver plantas resistentes aos fatores bióticos (como pragas, ervas daninhas) e abióticos (salinidade, desequilibro nutricional por escassez ou excesso de nutrientes, calor, alagamento/inundação, frio, seca), segundo [3] busca-se através do melhoramento genético obter-se incrementos em características; com ganhos gradativos e contínuos; reduzir ou eliminar a manifestação de características indesejáveis; acrescentar características de interesse ainda não disponíveis.

O Brasil por ter biomas diversificados e uma grande extensão territorial favorece o cultivo de grãos (arroz, feijão, soja algodão, hortaliças) sendo muito importante do ponto de vista socioeconômico para o desenvolvimento do país, isso torna bastante relevante as pesquisas sobre melhoramento genético, agregando assim valor aos vegetais e grãos, gerando visibilidade e confiabilidade no cenário internacional [4].

Nos últimos 20 anos com os avanços biotecnológicos, novas técnicas surgiram, que permitiram modificação de plantas através de engenharia genética, hoje em dia é possível inserir genes de outras espécies vegetais, ou mesmo genes de animais ou de bactérias originando plantas transformadas ou transgênicas (...)[5] a produção de plantas transformadas pode ser útil no combate a pragas pela produção de linhagens mais resistentes, na obtenção de plantas com maior valor nutricional, com partes mais vistosas de interesse ornamental, entre outras.

Fica evidente a necessidade de pesquisas voltadas para melhoramento genético, tanto do ponto socioeconômico, para torna-se mais lucrativo e reduzir os custos de produção, quanto para o consumidor final que terá maior qualidade do produto adquirido.

\section{A. Genética de População}

A genética de População busca explicar mudanças de frequências de alelos e suas distribuições, tentando desvendar fenômenos de adaptação ao meio ambiente, sob a influência de fatores como, seleção natural, mutação gênica, fluxo e derivação. Baseado em alguns aspectos primitivos em uma população como, ausência de seleção, mutação de loco, tamanho da população, ausência de migração.

0 estudo sobre populações tem como base o pool gênico, que são o conjunto total de genes que presente em todos os indivíduos da população, e graças às permutações, novos alelos se misturam aos já existentes, determinando uma enorme diversidade [6].

Theodosius Dobzhansky [7] define um conceito sobre a genética em populações; uma população é um conjunto de indivíduos que se reproduzem sexuadamente, compartilhando um conjunto de informações genéticas e mantendo um patrimônio gênico comum. Nesse contexto em 1908, Godfrey H. Hardy e Wilhem Weinberg, concluíram que, se nenhum fator evolutivo atuasse sobre uma população que satisfizesse certas condições, as frequências de seus alelos permaneceriam inalteradas ao longo das gerações, sendo esse principio conhecida atualmente como, Equilíbrio de Hardy-Weinberg. Dois 
princípios devem ser respeitados para que ocorra esse equilíbrio são esses: 1) a população deve ser muito grande (quanto maior, melhor); 2) a população deve ser panmítica (do grego pan, todos, e do latim miscere, mistura); Uma população que possua essas características, e na qual não ocorra nenhum fator evolutivo, tais como mutação, seleção ou migração, permanecerá em equilíbrio gênico, ou seja, as frequências dos alelos não sofrem alteração ao longo do tempo. Uma população na qual os indivíduos possam se reproduzir de forma sexuada com informações comuns do mesmo gene originário foi chamada de População mendeliana, com os seguintes aspectos:

Deve ser uma população muito grande; todos os cruzamentos podem ocorrer com igual probabilidade, casualmente, permitindo uma perfeita distribuição dos seus genes entre todos os seus indivíduos; uma população assim é conhecida como população panmítica; não deve estar sofrendo a ação da seleção natural, podendo manter com igual chance qualquer gene do seu conjunto, sem que nenhum tenha a tendência de ser eliminado; não há a ocorrência de mutações, que acrescenta novos genes ao patrimônio gênico da espécie; não há fluxo migratório entrando ou saindo dessa população, pois eles acrescentam ou removem genes do grupo original.

Naturalmente não existe população perfeita, apesar de ter uma grande amostragem, existem diversos fatores que o tornam inválidos como seleção natural ou mutações.

Faz-se fundamental a adoção de metodologias de seleção que proporcionem o aumento na frequência de alelos favoráveis, mantendo-se um tamanho efetivo que não restrinja ganhos consecutivos. Para isto, é necessário, nas primeiras etapas do programa, que as populações sejam conduzidas através de métodos de seleção recorrente, os quais levam a ganhos gradativos e consecutivos, sem restringir a variabilidade [3].

\section{B. Comparação entre Softwares Correlatos}

Nessa Subseção serão mostrados alguns softwares, que auxiliam pesquisadores, professores e estudantes em suas pesquisas Serão comparados o presente projeto em relação aos demais a fim de expandir a visão a respeito desses tipos de sistema. São eles: GENES [9], Popgene [10], Selegen [11], Carbópolis [12], Popgenelation.

Muitos são os softwares estimadores de diversidade genética, alguns foram apresentados na tabela 1, cada um com suas características próprias, a maioria em inglês, porém nenhum desses com caráter educativo e/ou instrutivo. 0 popgenelation possui além de não necessitar instalação, propõe uma interface intuitiva e simples; e possui a característica de ser educativo.
TABELA I - COMPARAÇÃO DOS SOFTWARES

\begin{tabular}{|c|c|c|c|c|c|}
\hline Plataforma & Genes & Popgene & Selegen & Carbópolis & Popgenelation \\
\hline $\begin{array}{c}\text { Web } \\
\text { Deskt } \\
\text { op }\end{array}$ & $\begin{array}{c}\text { Web e } \\
\text { Desktop }\end{array}$ & Desktop & Desktop & Web \\
\hline $\begin{array}{c}\text { Interface } \\
\text { simples }\end{array}$ & Sim & $\begin{array}{c}\text { Interface } \\
\text { Confusa } \\
\text { na versão } \\
\text { web, e } \\
\text { em modo } \\
\text { DoS na } \\
\text { versão } \\
\text { Desktop }\end{array}$ & Sim & Sim & Sim \\
\hline $\begin{array}{c}\text { Facilidade } \\
\text { de } \\
\text { instalação }\end{array}$ & Sim & Sim & Sim & Sim & Sim \\
\hline Educativo & Não & Não & Não & Sim & Sim \\
\hline $\begin{array}{c}\text { Código } \\
\text { aberto }\end{array}$ & Sim & $\begin{array}{c}\text { Gratuito } \\
\text { apenas } \\
\text { para } \\
\text { universi } \\
\text { dade e } \\
\text { órgãos } \\
\text { público } \\
\text { s }\end{array}$ & Sim & Sim \\
\hline
\end{tabular}

\section{METODOLOGIA}

Toda pesquisa deve submeter-se a um método científico, que é o caminho por onde o pesquisador deverá percorrer até chegar a seu destino final, portanto é importante saber por qual via deverá andar, isso significa dizer que necessário conhecer qual método se adequará melhor a sua pesquisa, para assim adota-la.

A presente pesquisa é metodológica, pois se refere à realidade, e nos leva a caminhos, formas ou procedimentos para alcançar um determinado fim. E aplicada, pois tem um objetivo concreto que é o software de melhoramento genético, que visa sanar um problema real, logo é algo prático, com uma solução concreta [8]. Quanto aos meios, a pesquisa é bibliográfica e de campo. Bibliográfica, pois, para fundamentação teórica foi necessário estudos relativos ao tema, como: melhoramento genético, sistemas educativos, linguagem de programação, tanto de forma direta como indireta. De campo pois houve entrevistas com profissionais da área de Ciências Biológicas, para que fosse possível levantar os requisitos para a construção do sistema e validação.

A metodologia adotada para o desenvolvimento do sistema se baseia no modo XP (Extreme Programming), o Scrum, que é um processo ágil que permite manter o foco na entrega do maior valor de negócio, no menor tempo possível, as necessidades de negócios é quem determinam as prioridades do sistema, qual parte do sistema será implementada primeiro, visando sempre agilidade no processo. 


\section{A. Material Utilizado}

Primeiramente foi utilizada uma ferramenta de capitação de áudio para a entrevista inicial com o objetivo de levantar os primeiros requisitos e ter a noção da viabilidade do sistema. Para a prototipação inicial das telas o Axure Pro 6.0 foi usado a fim de dar um norte no que se refere ao layout. 0 Astah Professional foi à ferramenta CASE escolhida para fazer a criação de diagramas de caso de uso. A ferramenta mais utilizada no projeto foi o NetBeans 7.3.1, responsável por toda a codificação, que foi feita na plataforma Java EE (Java Enterprise Edition), que se diferencia pelas demais por poder ser desenvolvida em nuvem, ou seja, não necessita a instalação na máquina, além de vir incluso o Tomcat 6.0, que é um servidor Web para aplicações em Java.

\section{B. Levantamento de Requisitos com o SCRUM}

Esse processo se iniciou a partir da compreensão do projeto apresentado de forma geral, como contexto e sua problemática, logo então reuniões periódicas foram necessárias para definição de requisitos e análises detalhadas, feitas de forma oral e com auxílio de mecanismos de captura de áudio, a fim de definir o escopo do projeto, bem como suas prioridades, limitações e dificuldades. 0 módulo prático do sistema, ou seja, a funcionalidade que trata dos cálculos foi definida como primeira a ser desenvolvida, a ferramenta CASE de modelagem Astah foi utilizada para criar o diagrama do Equilíbrio de Hardy-Weinberg.

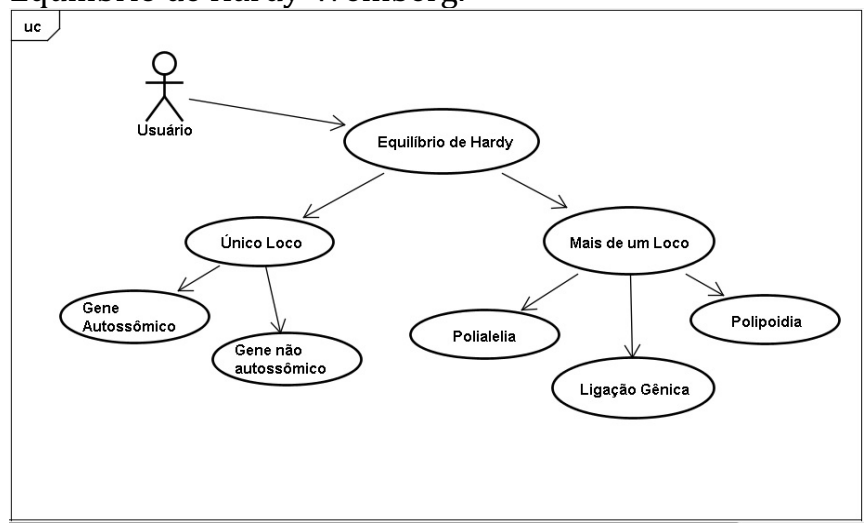

Figura 1. Diagrama Use Case

\section{B. Codificação do Sistema}

Com o processo de elicitação de requisitos completo e os primeiros modelos de caso de uso feitos, iniciou-se o processo de codificação, utilizando o método SCRUM, foram escritos os backlogs; uma lista de tarefas e das exigências e necessidades do produto final e foram feitos os sprints.

O Popgenelation foi dividido em dois módulos, teórico e prático, dentre o módulo prático, o Equilíbrio de HardyWeinberg foi a primeira funcionalidade a ser feita, tendo em vista que era a maior e mais trabalhosa, se dividindo em dois sub menus, Único Loco e Mais de um Loco, e cada um desses dividindo-se em novos sub menus, montando uma árvore, na primeira cadeia, Único Loco, se dividiu assim, Genes Autossômicos (não sexuais), e Genes Não Autossômicos (sexuais), e na segunda, Mais de um Loco, Polialelia, Ligação Gênica e Polipoidia, completando assim o primeiro módulo do sistema.

\section{POPGENELATION}

O sistema foi dividido em dois módulos previamente ditos, e serão explanados de forma separada cada um.

\section{A. Módulo Teórico}

Esse módulo é voltado para auxiliar pesquisadores e estudantes de nível intermediário ou iniciante, pois contém apenas explicações e exemplos, como equilíbrio de Hardy-Weinberg e suas subdivisões, como: Genes autossômicos e Polialelia.

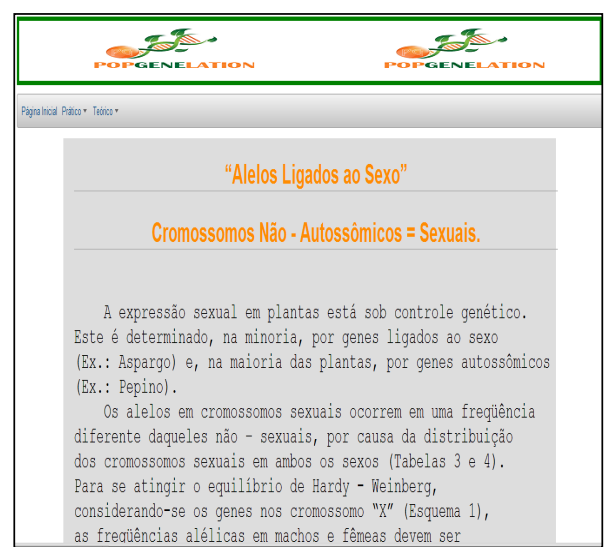

Figura 2. Tela do Sistema: modulo teórico

A figura 2 apresenta a tela inicial do módulo teórico, nele é possível aprender os conceitos acerca da genética de população. São apresentados também as fórmulas que são utilizadas para todos os cálculos. 0 conteúdo é parte do material didático das aulas de genética, fornecido pelo docente [6].

\section{B. Módulo Prático}

Esse módulo é responsável por realizar os cálculos. Como ilustra a figura 3, o "Equilíbrio de Hardy-Weinberg" se divide em subgrupos

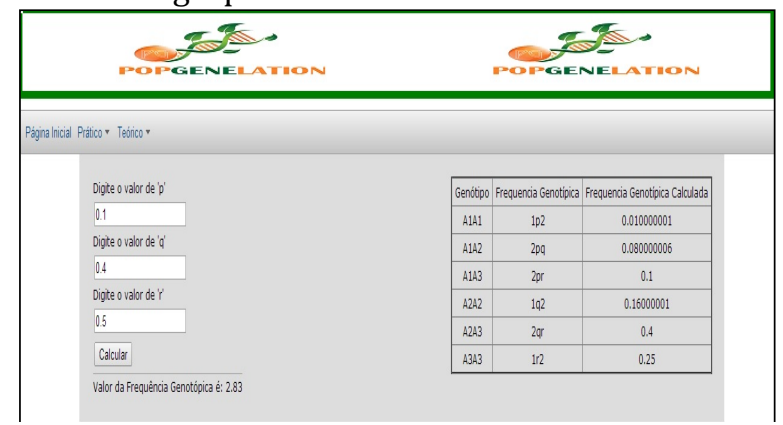

Figura 3. Tela do Sistema: modulo prático 
É necessário a inserção das frequências ' $p$ ', ' 'q' e 'r', que são solicitadas no sistema, para então realizar os cálculos de frequência, observando sempre que a soma das frequências deve ser igual a um. Concluída essa operação o sistema automaticamente irá gerar uma tabela da frequência genotípica, como apresentado na figura 3. Considerando A1, A2 e A3, sendo frequências respectivas de 'p', 'q' e 'r'.

Em caso de erros de digitação ou erros de dados, o sistema emite avisos informando como deverão ocorrer as inserções dos dados.

\section{RESULTADOS}

Em termos de usabilidade de um software, a Organização Internacional de Padronização - ISO, define como a capacidade do produto de software ser compreendido, seu funcionamento aprendido, ser operado e ser atraente ao usuário, para alcançar esses objetivos existem algumas sub-características a serem seguidas, a fim de medir seu nível de usabilidade, são elas: inteligibilidade (é fácil entender os conceitos utilizados?), Apreensibilidade (é fácil aprender a usar?), operabilidade (é fácil operar e controlar a operação?) e atratividade (é atraente?). Para atestar a efetividade dos objetivos propostos, uma análise de usabilidade foi realizada por meio de um questionário.

Os testes do sistema foram realizados com uma turma de 30 (TRINTA) discentes do curso de Ciências Biológicas da Universidade Estadual do Sudoeste da Bahia, Campus Jequié, com relação aos conhecimentos computacionais todos os participantes possuem computador, e mais de $60 \%$ utilizam o computador todos os dias, além de ficarem em média 5.4 horas conectados por dia, destes, 93\% não têm dificuldades ao navegar na internet, e $66.6 \%$ tem alguma dificuldade em instalar um software, problema esse que não terão com o Popgenelation, pois não necessita de instalação. Quando questionados se utilizariam esse tipo de ferramenta, e se melhoraria o sistema de ensino-aprendizagem, todos responderam afirmativamente as questões.

Por fim, foram então realizados a análise da usabilidade do Popgenelation, para isso alguns critérios foram focados, a saber:

Aspecto 1: Organização das informações, Aspecto 2: Facilidade de uso, Aspecto 3: Atratividade das telas, Aspecto 4: Desempenho do sistema, Aspecto 5: Capacidade de transmitir o assunto.

Para cada um desses critérios foi estabelecida uma classificação, dividindo-se em Muito Ruim, Ruim, Razoável, Bom e Ótimo, representadas no gráfico numericamente, indo de 1 a 5 , sendo 1 muito ruim e 5 ótimo. Por fim foram alcançados alguns resultados, que serão mostrados no gráfico 1.

Gráfico 1- Aspectos de Usabilidade do Sistema

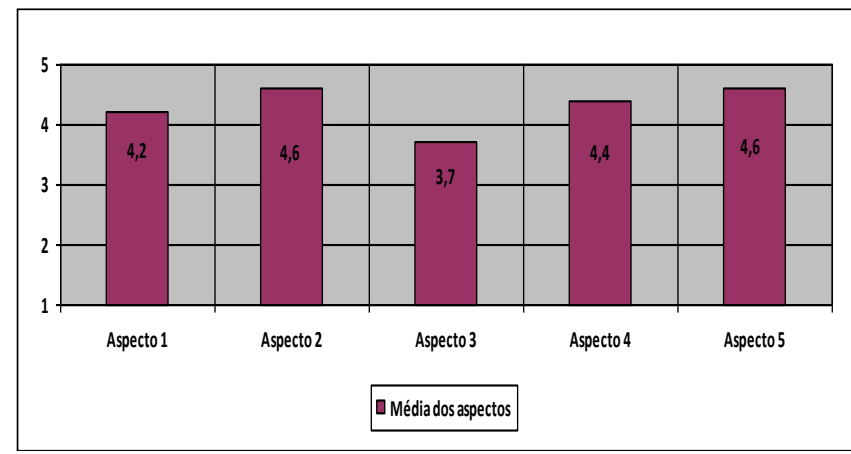

Por meio da análise de usabilidade foi possível afirmar que os objetivos foram alcançados no que se refere à um software educativo, de fácil compreensão, que seja bem organizado e intuitivo, facilitando a vida de pesquisadores e estudiosos na área de ciências biológicas, aprimorando os resultados das pesquisas e melhorando o paradigma de ensino-aprendizado.

\section{CONCLUSÃO}

Portanto, considera-se que o sistema desenvolvido, baseado nas pesquisas levantadas pode contribuir de forma positiva para facilitar o desenvolvimento de pesquisas voltadas para melhoramento genético, especificamente em genética populacional, automatizando cálculos matemáticos.

A mesma já está sendo utilizada nas aulas de Genética, ministradas no curso de Ciencias Biológicas da Universidade Estadual do Sudoeste da Bahia- Campus Jequié.

Assim sendo, o Popgenelation pode ser considerada uma ferramenta de auxilio para pesquisadores, docentes e discentes, devido ao uso da Tecnologia da Informação aliada à educação. A grande proposta do sistema era não ser apenas uma calculadora, com resultados expostos sem qualquer explicação, e sim exemplificar cálculos, deduzir fórmulas, explicar conceitos, tornando-se um meio facilitador.

Por meio dos testes de usabilidade pode-se perceber a importância do software desenvolvido, e sua finalidade que é auxiliar os pesquisadores e acadêmicos na área de ciências biológicas, pois foi alcançada sua proposta de ter boa usabilidade e eficiência no que foi proposto, que é uma das características necessárias para desenvolver um sistema educativo.

Análises futuras sobre funcionalidades serão realizadas a fim de obter melhorias continuas no sistema, como ícones de acesso rápido na tela dos cálculos com explicações, legendas e deduções, aumentando a interatividade entre usuário e máquina.

\section{REFERENCIAS}

[1] SKINNER , B. F.The technology of teaching. New York: Appleton-Century Crofts. 1968. 
[2] BAIOTTO, C.R; JÚNIOR, J.J.B; MÉA, A.R.D; NUNES, I. D; Software e realidade virtual como apoio didático do ensino de genética. Universidade de Cruz Alta/

[3]MORELLO, Camilo de Lelis; FREIRE, Eleusio Curvelo. Estratégias para o Melhoramento Genético do Algodoeiro no Brasil. 2005. Disponível em: http://www.cnpa.embrapa.br/produtos/algodao/publicac oes/trabalhos cba5/317.pdf.

[4]DOS SANTOS. C. A. O melhoramento genético de plantas e animais no brasil: a participação da associação brazileira de acclimação, século xix. Disponível em: http://www.sbhc.org.br/resources/anais/10/134324622 6 ARQUIVO CASantos 1 .Artigo.13SNHCT-2012.pdf.

[5] UNICRUZ, $51^{\circ}$ Congresso Brasileiro de Genética. São Paulo, 2005

[6] Amaral, C. L. F. Fundamentos de Genética de Populações Vegetais no Melhoramento de Plantas. 2011.

[7]DOBZHANSKY, T. Evolution in the tropics. American Scientist, 1950

[8]VERGARA, S. C. Projetos e relatórios de pesquisa em administração. 11. Ed. - São Paulo: Atlas, 2009.

[9] CRUZ, C. D. Programa Genes - Aplicativo Computacional em Estatística. Aplicada a Genética. São Paulo: Cielo, 1998.

[10] Yeh FC, Yang RC, Boyle T. 1999.POPGENE. Microsoft Windows-based freeware for population genetic analysis. Release 1.31. Edmonton: University of Alberta.

[11] RESENDE, M. D. V. de. O Software Selegen REML/BLUP. Campo Grande - São Paulo: documentos EMBRAPA, 2006.

[12] EICHLER, Marcelo; DEL PINO, José Claudio. Carbópolis, um Software Para Educação Química. nº11, 2000.

Disponível

em:http://qnesc.sbq.org.br/online/qnesc11/v11a02.pdf 